\title{
FDI, Spillover Effect and Green Total Factor Productivity (GTFP) - Research from the Perspective of Regional Heterogeneity
}

\author{
Hang Xiao ${ }^{1, *}$, Xiangjian Zhang $^{1}$ \\ ${ }^{1}$ Institute of Finance \& Economics, Shanghai University of Finance and Economics \\ *Corresponding author: Hang Xiao
}

\begin{abstract}
The report of the 19th National Congress of the Communist Party of China emphasized the need to promote green development and strengthen the environmental protection system. China's introduction of foreign investment has gradually shifted from emphasis on "quantity" to "quality" in the context of the new normal. In view of this, this paper discussed the mechanism of impact of FDI on China's regional GTFP with the relationship between FDI and the regional GTFP as the logic starting point. The research results show that FDI has in general exerted a "pollution halo" effect in China, which affects the regional GTFP through technology and human capital spillover effects; FDI has non-linear impact on GTFP at different levels of environmental regulation and marketization; "pollution haven", "bottom line competition" and other phenomena will occur at low levels of environmental regulation and marketization; FDI will inhibit the increase in China's regional GTFP; the impact of FDI on GTFP is regionally different, and the western and northeastern regions are "pollution havens" in China.
\end{abstract}

\section{Introduction}

With the transformation of the economic development model, the Chinese government has gradually raised the environmental "threshold" in the process of using FDI, paying more attention to the balanced development of economy and ecological environment and the reduction of the pressure on the energy environment. In summary, FDI has dual impacts on the environment and economy of developing countries. Industry linkage effect, demonstration effect and competitive effect of FDI affect the technology spillover and factor accumulation of the host country, thereby affecting the innovation capability, $R \& D$ input and human capital accumulation of its enterprises and thus GTFP. Due to the crowding-out effect, the positive or negative nature of the three impacts above depends on whether enterprises in the host country break through the path of reliance on the technology of FDI introduction and form a virtuous circle of "introduction-absorption-innovation-output". As far as China is concerned, a considerable amount of FDI has entered industries with high pollution and high energy consumption as it required foreign investments to help it realize industrialization due to its economic development at the initial stage and uneven regional development, the quality requirements for FDI were not high in the early stage and local governments had "bottom line competition". Therefore, the degree of marketization and the level of environmental regulation play a regulatory role in the "FDI-GTFP" relationship when changes in regional environmental regulation and marketization levels are considered, which is mainly manifested in the following: strict environmental regulation inhibits the inflow of low-quality FDI and attracts clean FDI, which is conducive to the improvement of the regional GTFP. The higher the degree of marketization, the smaller the administrative intervention of the local government in the economy, the fiercer the competition among enterprises and the freer the flow of factors. All this is conducive to the survival of the fittest among enterprises and the natural screening of low-quality FDI and to the adoption of advanced management experience and technology by local enterprises through frequent technical exchanges and flow of personnel.

Therefore, this paper proposes:

Hypothesis 1: the inflow of FDI will positively promote GTFP as there are higher requirements for it;

Hypothesis 2: The impact of FDI on GTFP is non-linear at different levels of environmental regulation and marketization.

\section{GTFP measurement and model setup}

\subsection{GTFP measurement}

Scholars have measured and decomposed GTFP with different methods based on the conditions of China (for example, Zhu X, Chen Y and Feng C,2018; Liu and Xin,2019; Xia F and Xu J,2020). In this paper, the regional GTFP will be measured based on the 
three-phase DEA (Fried, 1999, 2002) in view of the fact that the influence of external environmental factors and random factors is often ignored in previous studies. The total energy consumption, physical capital stock and the number of employees will be selected as input indicators, GDP as the expected output indicator and carbon dioxide emission as the undesirable output indicator. GTFP is affected by economic and social factors besides input and output. Differences in regional development levels will directly affect resource input and pollutant emissions. Therefore, the proportion of the secondary industry in GDP and the full time equivalent of R\&D personnel are selected as environmental factors in this paper. In this paper, the data of 30 provinces, cities and autonomous regions in mainland China from 2000 to 2016 is selected as research samples. Tibet is not considered in the study due to the serious lack of data in some years. The key explanatory variable is FDI, which is measured by the proportion of total foreign investment in GDP. Relevant data are derived from the statistical yearbooks of provinces, cities and autonomous regions, China City Statistical Yearbook, China Statistical Yearbook on Environment and China Energy Statistical Yearbook in 2001 to 2017.

\subsection{Measurement model setup}

In the empirical part, we first consider the total effect of FDI on GTFP to test whether the "pollution haven" effect or the "pollution halo" effect exists in China.

$$
G T F P_{i t}=\beta_{0}+\beta_{1} F D I_{i t}+\beta_{3} X_{j i t}+\varepsilon_{i t}
$$

Further, the panel threshold regression (PTR) model proposed by Hansen (1999) is used in order to test the non-linear impact of FDI on GTFP at different levels of technology spillover, human capital spillover, marketization and environmental regulation, which can not only estimate the threshold value, but also test the significance of the endogenous "threshold effect". In this paper, a panel threshold model is set up with levels of innovation, $\mathrm{R} \& \mathrm{D}$ input, environmental regulation and marketization as threshold variables respectively:

$G T F P_{i t}=\beta_{i t}+\beta_{1} F D I_{i t}+\beta_{2} F D I_{i t} I\left(Z_{i t}<\delta\right)+\beta_{3} X_{j i t}+\varepsilon_{i t}(2)$

GTFP $_{i t}$ is as shown above. $Z_{i t}$ includes levels of innovation, R\&D input, environmental regulation and marketization which are respectively threshold variables for measuring GTFP. $I(\bullet)$ is an indicative efficient; $\delta$ is the threshold value calculated. Different threshold variables correspond to different threshold values. $\beta_{2}$ is the threshold regression coefficient of the key variable $F D I_{i t} I$.

\section{Empirical results and analysis}

\subsection{FDI and regional GTFP}

Table 2 shows the effect of FDI on the efficiency of regional green economic growth. Model 1 shows basic regression results. For models 2 and 3, robustness test was conducted through replacement of the explained variable. In addition, considering the endogenous problem of the model, regression analysis was conducted with the generalized method of moments (GMM) estimation proposed by Blun-dell et al. (1998). For models 4 to 6 , robustness test was conducted through GMM regression. According to the regression results of model 1, FDI has a significant positive impact on the regional GTFP at a significance level of 5\%. For China, the current FDI has more obvious "pollution halo effect". To ensure the reliability of regression results, models 2 and 3 were subject to regression with GTFP replaced by the energy consumption per unit of GDP (the ratio of total energy consumption to GDP) and the emission intensity per unit of GDP (ratio of emissions of "three exhaust gases" to GDP) respectively.

Table 1 Regression results

\begin{tabular}{|c|c|c|c|c|c|c|}
\hline & \multicolumn{3}{|c|}{ Two-way fixed effects model estimation } & \multicolumn{3}{|c|}{ GMM estimation } \\
\hline & Model (1) & Model (2) & Model (3) & Model (4) & Model (5) & Model (6) \\
\hline & GTFP & Sec_gdp & Outgas_gdp & GTFP & Sec_gdp & Outgas_gdp \\
\hline \multirow[t]{2}{*}{ FDI } & $0.0226 * *$ & $-0.363 * *$ & $-69.99 * *$ & $0.0262 *$ & -0.207 & -31.54 \\
\hline & $(2.37)$ & $(-2.17)$ & $(-2.13)$ & $(1.91)$ & $(-1.10)$ & $(-0.92)$ \\
\hline $\begin{array}{l}\text { Control } \\
\text { variable }\end{array}$ & Controlled & Controlled & Controlled & Controlled & Controlled & Controlled \\
\hline $\begin{array}{c}\text { Region and } \\
\text { year }\end{array}$ & Controlled & Controlled & Controlled & Controlled & Controlled & Controlled \\
\hline \multirow[t]{2}{*}{ cons } & $0.727 * * *$ & $9.419 * * *$ & $1555.8 * * *$ & $0.503 * * *$ & $11.17 * * *$ & $1168.6^{* * *}$ \\
\hline & $(9.9)$ & $(7.29)$ & $(5.43)$ & (3.96) & $(6.12)$ & $(3.43)$ \\
\hline $\mathrm{N}$ & 451 & 480 & 300 & 451 & 480 & 300 \\
\hline
\end{tabular}

Note: The numbers in parentheses are standard errors; $* * *, * *$ and $*$ indicate that they have passed the test at a significance level of $1 \%, 5 \%$, and $10 \%$ respectively. The same below.

\subsection{Channel through which FDI affects GTFP: non-linear relationship test}

To further investigate the non-linear impact of FDI on GTFP, the threshold model can be used for regression estimate (model 3). Table2 shows the regression results of the threshold test of formula (3). The effect of FDI on GTFP varies with the change of the threshold variable. The regression results in columns 1-3 show that the FDI coefficient is significantly negative at a low marketization level and becomes significantly positive as 
the marketization level breaks through the threshold value. The regression results in columns 4-7 show that the FDI coefficient is significantly positive even at a low level of environmental regulation and continues to increase as the level of environmental regulation improves.

Table2 Threshold test regression results

\begin{tabular}{cccccccc}
\hline & \multicolumn{3}{c}{ Marketization level (market) } & \multicolumn{5}{c}{ Environmental regulation level (ER) } \\
\hline & $<3.37$ & $(3.37,5.82)$ & $>=5.82$ & $<2.182$ & $(2.182,3.095)$ & $(3.09,5.786)$ & $>=5.786$ \\
\hline FDI*I & $-0.161^{* * *}$ & $-0.156^{* * *}$ & $0.195^{*}$ & $0.0438^{* * *}$ & $0.0660^{*}$ & 0.00755 & -0.0251 \\
\hline & $(-7.47)$ & $(-7.36)$ & $(1.76)$ & $(2.84)$ & $(1.84)$ & $(0.24)$ & $(-1.56)$ \\
\hline $\begin{array}{c}\text { Control } \\
\text { variable }\end{array}$ & Controlled & Controlled & Controlled & Controlled & Controlled & Controlled & Controlled \\
\hline Constant & $0.470^{* * *}$ & $0.526^{* * *}$ & $0.282^{* * *}$ & $0.507^{* * *}$ & $0.504^{* * *}$ & $0.504^{* * *}$ & $0.342^{* * *}$ \\
\hline $\mathrm{N}$ & $(12.60)$ & $(13.51)$ & $(6.32)$ & $(13.27)$ & $(13.22)$ & $(13.22)$ & $(8.35)$ \\
\hline & 451 & 451 & 451 & 451 & 451 & 451 & 451 \\
\hline
\end{tabular}

Table 3 lists the regression results with levels of innovation, R\&D input and human capital accumulation as threshold variables. The regression results in columns 1-3 show that the introduction of FDI will have a significant negative impact on the regional GTFP at a low level of independent innovation of local enterprises; however, the environmental benefits of FDI will gradually emerge as the innovation level increases.

Table3 Threshold test regression results

\begin{tabular}{|c|c|c|c|c|c|c|c|c|c|}
\hline & \multicolumn{3}{|c|}{ Innovation level (patent_pop) } & \multicolumn{3}{|c|}{ R\&D input level (rd) } & \multicolumn{3}{|c|}{ Human capital level (rlab) } \\
\hline & $<0.001$ & $\begin{array}{c}(0.001,0.00 \\
2)\end{array}$ & $>=0.002$ & $<4187.8$ & $\begin{array}{c}(4187.8,11684 \\
2) \\
\end{array}$ & $>=116842$ & $<466.564$ & $\begin{array}{c}(466.564,8274 \\
.15) \\
\end{array}$ & $\begin{array}{c}>=8274.1 \\
5\end{array}$ \\
\hline FDI*I & $\begin{array}{c}-0.0869^{* *} \\
*\end{array}$ & $0.0782 * * *$ & $0.0899 * * *$ & $-0.0612 * * *$ & $0.0931 * * *$ & $0.0607 * *$ & $-0.0927 * * *$ & $0.155^{* * *}$ & $0.245^{* * *}$ \\
\hline & $(-4.04)$ & $(3.53)$ & (3.72) & $(-3.59)$ & $(4.32)$ & $(2.55)$ & $(-4.83)$ & (2.99) & (5.11) \\
\hline $\begin{array}{c}\text { Control } \\
\text { variable }\end{array}$ & Controlled & Controlled & Controlled & Controlled & Controlled & $\begin{array}{c}\text { Controlle } \\
\mathrm{d}\end{array}$ & Controlled & Controlled & $\begin{array}{c}\text { Controlle } \\
\mathrm{d}\end{array}$ \\
\hline Constant & $0.643 * * *$ & $0.636^{* * *}$ & $0.386 * * *$ & $0.527 * * *$ & $0.520 * * *$ & $0.398 * * *$ & $0.429 * * *$ & $0.411 * * *$ & $0.289 * * *$ \\
\hline & $(16.84)$ & $(16.86)$ & $(10.41)$ & $(12.93)$ & $(13.09)$ & $(10.68)$ & $(11.32)$ & $(11.12)$ & $(7.72)$ \\
\hline $\mathrm{N}$ & 451 & 451 & 451 & 451 & 451 & 451 & 451 & 451 & 451 \\
\hline
\end{tabular}

\subsection{Regional heterogeneity analysis}

It is found through group regression by region that the impact of FDI on China's regional GTFP is heterogeneous and regionally different. FDI has a positive impact on GTFP in the eastern and central regions and a significant negative impact on the western and northeastern regions, indicating whether the introduction of FDI brings about the "pollution haven" or "pollution halo" effect is related to the regional development level and resource endowment. The samples were further grouped and regressed according to the level of environmental regulation, the scale of economic development and the level of industrial structure. ${ }^{1}$ According to the regression results, firstly, the level of environmental regulation directly affects the direction of FDI's effect on GTFP. In areas at a high level of environmental regulation, foreign investment is screened and industries with high pollution and high energy consumption are eliminated, and foreign-funded enterprises will also use clean technology in the production process to increase the regional GTFP and exert the "pollution halo" effect due to the strict implementation of environmental protection policies and standards. "Pollution haven" still exists in areas at a low

\footnotetext{
1 Samples were grouped into regions with high and low development levels based on the median. The specific regression results are not included in the text due to space limitations.
}

level of environmental regulation. Secondly, the positive effect of FDI on GTFP is not significant in areas with a larger economic scale, while the introduction of foreign investment can improve the regional GTFP significantly in areas with a small economic development scale. Finally, the advancement level of industrial structure has an equally significant impact on the improvement of FDI's environmental benefits. In areas with a more advanced industrial structure, the government has set higher thresholds for attracting investment and will "actively choose" to introduce high-quality FDI and cooperate in the gradual transformation of the local industrial structure from industries with high energy consumption and high pollution to clean industries with low energy consumption and make a positive impact on the rationalization and advancement of local industries. Meanwhile, local enterprises can improve the production efficiency and reduce pollution levels with reference to the advanced technology and clean production pattern of foreign investment, thereby promoting the increase in GTFP.

\section{Conclusions}

Environmental protection and economic development are issues of concern all over the world. The rate of human consumption of natural resources has increased year by year since the second industrial revolution. As the world's largest energy consumer, China has an unshirkable responsibility for coping with global warming and reducing carbon emissions. One of the most important aspects of the "community of a shared future for 
mankind" is to jointly respond to the ecological crisis that has occurred on a global scale. In particular, as China's development has entered a new era, how to change the pattern of economic development and how to achieve intensive development have become worthy of discussion. This paper studies the effect of FDI on the regional GTFP and its specific mechanism of action based on the inter-provincial panel data of China from 2000 to 2016. The research results show that (1) the inflow of FDI will in general improve China's GTFP, exerting a "pollution halo" effect; (2) FDI affects the regional GTFP through technology and human capital spillover effects, but its impact varies at different levels of innovation, R\&D input and human capital. A "pollution haven" will occur at a low level of innovation, R\&D input and human capital. FDI will make a positive impact on the regional GTFP only when the three break through the threshold; (3) The impact of FDI on the regional GTFP is non-linear at different levels of marketization and environmental regulation. The environmental benefits of FDI will increase as the level of marketization improves. Once environmental regulation starts, FDI will make a positive impact on the regional GTFP. However, a "crowding out effect" will occur as foreign investment will transfer the destination in consideration of costs if the level of environmental regulation is close to a higher threshold; (4) There are regional differences in the impact of FDI on GTFP. The western and northeastern regions are "pollution havens" in China. The environmental benefits of FDI vary in regions with different economic scales, development levels and industrial structure levels.

\section{References}

1. Kui-Yin C, Lin P. Spillover effects of FDI on innovation in China: Evidence from the provincial data[J]. China Economic Review, 15(2004)

2. Ullah A, Zhao X, Kamal M A, et al. Environmental regulations and inward FDI in China: Fresh evidence from the asymmetric autoregressive distributed lag approach $[\mathrm{J}]$. International Journal of Finance \& Economics, 3(2020).

3. Ashford N A, Bluestone B, Freeman P, et al. Globalization and the environment[J]. Journal of Public Health Policy, 23(2002)

4. Eskeland, Gunnar S.*Harrison, Ann E. Moving to greener pastures? Multinationals and the pollution haven hypothesis[J]. Journal of Development Economics, 70(2003)

5. Abdouli M, Kamoun O, Hamdi B. The impact of economic growth, population density, and FDI inflows on $\mathrm{CO} 2$ emissions in BRICTS countries: Does the Kuznets curve exist?[J].Empirical Economics, 54(2018)

6. Luo Y, Xue Q, Han B. How emerging market governments promote outward FDI: Experience from China[J].Journal of World Business, 45(2010)

7. Chen Q, Maung M, Shi Y, et al. Foreign direct investment concessions and environmental levies in China [J]. International Review of Financial Analysis, 36(2014)

8. Singhania M, Saini N. Demystifying pollution haven hypothesis: Role of FDI [J]. Journal of Business Research,123(2021)

9. Antweiler, Werner, Copeland, et al. Is Free Trade Good for the Environment? [J].American Economic Review, 2001.

10. Karen, Fisher-Vanden, and, et al. What is driving China's decline in energy intensity? [J]. Resource \& Energy Economics, 2004.

11. Reppelin-Hill V. Trade and Environment: An Empirical Analysis of the Technology Effect in the Steel Industry $[\mathrm{J}]$. Journal of Environmental Economics \& Management, 38(1999)

12. Eskeland $\mathrm{G} \mathrm{S}^{*} \mathrm{~A}$ E. Moving to greener pastures? Multinationals and the pollution haven hypothesis[J]. Journal of Development Economics, 70(2003)

13. Liu Z, Xin L. Has China's Belt and Road Initiative promoted its green total factor productivity? Evidence from primary provinces along the route[J]. Energy Policy, 129 (2019)

14. Wei-Bing L I, Liu F W, Bin W, et al. Can Environmental Regulation Promote GTFP? -Evidence from the Two Control Zones Policy. Journal of Huazhong University of Science and Technology(Social Science Edition), 2019.

15. Xia F, Xu J. Green total factor productivity: A re-examination of quality of growth for provinces in China[J]. China Economic Review, 2020, 62. Harold O. Fried, Shelton S. Schmidt, Suthathip Yaisawarng.Incorporating the Operating Environment into a Nonparametric Measure of Technical Efficiency[J]. Journal of Productivity Analysis, 12 (1999)

16. H.O. Fried, C.A.K. Lovell, S.S. Schmidt, S. Yaisawarng. Accounting for environmental effects and statistical noise in data envelopment analysis[J]. Journal of Productivity Analysis, 17 (2002) 